\title{
EFFECT OF CONSECUTIVE AEROBIC AND
}

\author{
RESISTANCE EXERCISE ON CORTISOL,
}

CREATINE KINASE AND IMMUNOGLOBULIN

A RESPONSES IN MALE ATHLETES

\author{
By \\ ${ }^{1}$ Ahmed SM and ${ }^{2}$ Darwish F \\ ${ }^{I}$ Department of Track and Field, ${ }^{2}$ Department of Biological Science and Sports Health, \\ Faculty of Physical Education for Women, Gizira, Helwan University
}

\begin{abstract}
Introduction: Immunoglobulin A ( $\operatorname{IgA})$ is the main class of antibodies present in the body secreted fluids such as saliva, tears or mucus from the intestines. The meaning of IgA in serum is still unclear. It was postulated that this immunoglobulin performs a complementary role in the neutralization of the pathogens, which defeated the mucosal barrier, as well as macrophage activation, and removal of immune complexes formed with the participation of this isotype. Aim of Work: To investigate the effects of resistance exercise on Cortisol, Immunoglobulin A (IgA), and Creatine kinase (CK) responses of male students. Materials and Methods: Ten subjects (mean age $21.0 \pm$ 1.5 years) completed two trail, aerobic Treadmill exercises (60\% VO2max; 45-min) and resistance ( $80 \%$ 1RM; 45-min) exercise concurrently; each subject was his own control. Blood samples were collected pre-exercise, post-exercise, and 3 hours after exercise. One-way ANOVA with repeated measure and LSD post-hoc tests were used to evaluate changes in Cortisol, CK, and IgA during baseline and exercise periods. Results: During baseline, there were no differences between exercise day (ED) values and those obtained at rest day (RD) for Cortisol, CK, and IgA. After exercise, Cortisol concentration in ED was significantly higher than $\mathrm{RD}(\mathrm{p}<0.05)$; however, changes in IgA and CK responses were not significant. Conclusions: This type of consecutive exercise didn't increase susceptibility to upper respiratory tract infection and muscle damage. Therefore, it can be useful for the preparation phase of training for athletes.

Key words: Immunoglobulin A - Creatine kinase - Cortisol- Consecutive exercises factory, El-Minia
\end{abstract}




\section{Introduction}

Immunoglobulins

are

a

heterogeneous group of proteins of the immune system. All immunoglobulins are composed of four polypeptide chains: two light (L) and two heavy $(\mathrm{H})$, joined by disulfide bonds in macromolecular compound. Immunoglobulin A is the main class of antibodies present in the body secreted fluids such as saliva, tears or mucus from the intestines. It is generally recognized that $\operatorname{Ig} \mathrm{A}$, due to its dominance in the immune system of mucous membranes, is the first line of defense against harmful environmental factors. The secretion and composition of saliva depends on the activity of the sympathetic and parasympathetic nervous systems (Houmard et al, 1990). Physical activity, stimulating the autonomous nervous system, may reduce the amount of saliva and/or inhibit its secretion. The relationship between physical activity and the suppression of the immune system is not fully understood, but it is known that moderate intensity exercise can improve immune defenses, while extreme effort can reduce them by creating an increased risk of upper respiratory tract inflammation (URTI) (Walsh et al, 1999) .In athletes, the lowest risk of upper tract infection was connected with the case of moderate intensity exercise. It is now believed that the relationship between exercise volume and the risk of URTI has the shape of the letter "J". This means that both too little and too much physical activity may increase the risk of upper respiratory tract infection (Proctor and Carpenter, 2007) .Training optimization and correct balance between exercise and rest periods may reduce the risk of adverse changes in the immune system and decrease the frequency of URTI (Walsh et al, 1999).

The immunoglobulin $\mathrm{A}(\operatorname{Ig} \mathrm{A})$ is the major glycoprotein described in recent years. It is produced by mature B cells (Nieman et al, 2000) in the blood and is secreted into bodily fluids (Mestecky et al, 1989), such as saliva, tears, as well as nasopharyngeal, bronchial, intestinal and urogenital secretions (Gleeson, 2000 - McGhee et al, 1989), and it penetrates freely through the mucous membranes. Salivary immunoglobulin A (IgA) provides a valuable defense against potential pathogens by preventing colonization and replication on the mucosal surfaces of the upper respiratory tract (Mackinnon, 1992). The secreted $\operatorname{IgA}$ prevents antigens and microbes from adhering to and 
penetrating the epithelium (immune exclusion), interrupts replication of intracellular pathogens during transcytosis through epithelial cells (intracellular neutralization), and binds antigens in the lamina propria, thus facilitating their excretion through the epithelium back into the lumen (immune excretion) (Gleeson and Pyne ,1993- Lamm, 1998). Reduced concentrations or reduction in the release of Salivary IgA may allow for increased pathogenesis via the mucosal surface (Ostergaard, 1977). It has been shown that lower concentrations of IgA or chronic IgA deficiencies are associated with an increased frequency of upper respiratory tract infection (URTI) episodes (Gleeson et al, 1999 - Gleeson and Pyne, 1993), recurrent URTI (Isaacs et al, 1984), or reduced protection against certain infections (Asahi et al, 2002).

The human body produces two types of immunoglobulin A: serum and secretory. Their total daily production is $66 \mathrm{mg}$ per $\mathrm{kg}$ body weight (McGhee et al, 1989 - Mestecky et al, 1989). The immune response of the IgA is triggered by many pathogens and is mainly induced locally in the mucous membranes. The IgA secretion into saliva is stimulated by various factors such as stress or physical activity (Daly et al , 2005). The secretion and composition of saliva depends on the activity of the sympathetic and parasympathetic nervous systems. The physical activity, stimulating the autonomous nervous system, may reduce the amount of saliva and/ or inhibit its secretion (Proctor and Carpenter, 2007)

There are reports demonstrating that $\operatorname{IgA}$ concentrations are suppressed in response to high intensity exercise (Gleeson et al 1999 -Tharp, 1991) remain either unaltered (McDowell 1991-Volfinger, et al 1994) or are elevated in response to moderate-low intensity exercise (Ljungberg et al, 1997). However, several studies have also shown a stable secretion rate of $\operatorname{IgA}$ following tennis drills (Nieman et al, 2000), a soccer match (Bishop et al 2000), or cycling (Blanni et al, 1998). Jemmott and McClelland 1989 concluded from a meta-analysis of nine studies that the level of $\operatorname{IgA}$ secretion might indicate vulnerability toward URTI. Mackinnon and Hooper ,1994 further suggested that the protective effect might depend not only on $\operatorname{IgA}$ concentration, but also on salivary flow rate. 
Although the physiological mechanisms underlying the temporary suppression of various aspects of the immune function after high-intensity exercise are still unclear, it is likely that both neural and endocrine factors influence the immune response to exercise (Fleshner, 2000- Pedersen and Hoffman 2000).

Cortisol is the end product of the neuroendocrine stress response in humans. Although high levels of Cortisol have been demonstrated to inhibit antibody production in vitro (Ambrose, 1996), studies have suggested that elevated glucocorticoids are necessary, but not sufficient, to suppress the antibody response (Fleshner, 2000). However, while some studies have reported no acute changes in cortisol secretion in response to resistance exercise (Dohi et al 2001- McDowell et al, 1991), others have reported changes (Rahimi et al 2010).

Creatine kinase $(\mathrm{CK})$ is found predominantly in muscle and is released into circulation during muscular lesions. Therefore, serum CK activity has been theoretically expected to be useful as a marker in exercise physiology and sports medicine for the detection of muscle injury and overwork (Houmard et al 1990). However, previous studies on CK release have not clearly demonstrated its value as a marker for these states (Newham et al, 1987). Numerous studies have evaluated changes in CK activity after exercise and found that it differs markedly according to exercise conditions. For example, in isometric muscle contraction exercise, peak serum CK activity is observed relatively early, 24-48 h after exercise (Kirwan et al, 1986), whereas it is seen 3-7 days after exercise in eccentric muscle contraction exercise (Newham et al, 1987), and a biphasic pattern is observed in weight training (Tokuda et al, 1985).

Totsuka et al,2002 reported that CK response depends on individual fitness level. They show that peak CK values during the bicycle exercise correlated with workload/ cross sectional area of the quadriceps femurs muscle, workload/ volume of the quadriceps femurs muscle, and knee extensor strength/body mass. However, according to inconsistency in previous results, there are no quantitative results concerning immune response to exercise. To our knowledge there is no study that evaluates the effect of single bout of consecutive aerobic 
and resistance exercise on immune response. Therefore, the purpose of this study was to determine the effect of a single bout of consecutive aerobic and resistance exercise on Cortisol, IgA, and $\mathrm{CK}$ responses in male students.

\section{Aim of Work}

To investigate the effects of resistance exercise on Cortisol, Immunoglobulin A (IgA), and Creatine kinase $(\mathrm{CK})$ responses of male students.

\section{Material and Methods}

Participants: Ten male athletes Track \& Field Egypt national team for long-distance and cross-country took part in the study. They were actively involved in first preparatory phase for Fitness endurance \& resistance training 3 days weekly for 2.5- 3 hours on average every day. Characteristics of the subjects are reported in Table 1. Before the start of the study, subjects provided written informed consent. They were asked not to perform any strenuous exercise or consume medication for 2 days before each trial.

Preliminary

measurements:

Maximal aerobic capacity (VO2max) was estimated using the Fox protocol (heart rate response to $5 \mathrm{~min}$ of cycle ergometry at $150 \mathrm{~W}(6300-$ $\left.19.26^{\circ} \mathrm{x}(\mathrm{HR} 5 \mathrm{~min})=\mathrm{VO} 2 \mathrm{max}\right)$; $($ Dohi et al, 2001). Also, muscular strength was measured at the beginning of the study. Strength was assessed by one repetition maximum (1-RM) for bench press, leg press, leg extension, leg curl, lats pull-down, and biceps curl.

Table 1: Characteristics of subjects variables (mean \pm SD) male athletes $(n=10)$

\begin{tabular}{|c|c|}
\hline Characteristics & Mean \pm SD \\
\hline Age (years) & $21.7 \pm 2.51$ \\
\hline Weight $(\mathbf{k g})$ & $60.77 \pm 5.7$ \\
\hline Body height $(\mathbf{c m})$ & $173.3 \pm 4.7$ \\
\hline Skeletal Muscle Mass (kg) & $35.42 \pm 4.8$ \\
\hline Body fat $(\%)$ & $9.09 \pm 3.6$ \\
\hline BMI $(\mathbf{k g} / \mathbf{m} \mathbf{2})$ & $20.73 \pm 1.5$ \\
\hline VO2 $\mathbf{m a x}(\mathbf{m l} / \mathbf{k g} / \mathbf{m i n})$ & $45.62 \pm 6.7$ \\
\hline
\end{tabular}


Following warm-up for the 6 resistance exercise testing, subjects selected a weight with which they felt they could complete three repetitions. At this weight, they only performed one repetition. Subjects then selected a weight they felt would be their 1-RM and attempted one repetition with this weight. Following successful attempts, weight was increased by $2-5 \mathrm{~kg}$ for subsequent 1-RM attempts. The 1-RM was usually reached in less than 6 sets, including the warm-up set. There was 3 min of rest between attempts, and two assistants changed the weight on the bar between attempts.

Procedures: The subjects completed trials in a counterbalanced order. For the afternoon exercise trial, subjects reported to the laboratory at 14:00 after fasting from 22:30 the previous day to 10:30 a.m. They then performed $45 \mathrm{~min}$ cycling at $60 \% \mathrm{VO} 2 \mathrm{max}$ and $45 \min 6$ free-weight resistance exercise in the following order: bench press, leg press, leg extension, leg curl, lats pull-down, and biceps curl. Exercises consisted of 3 sets of 8 repetitions ( $80 \%$ 1-RM), with a 2-min rest between sets and a 3-min rest between exercises. The laboratory temperature and relative humidity were
$21.4 \pm 0.4^{\circ} \mathrm{C}$ and $64 \pm 3 \%$, respectively. Blood and saliva samples were taken during baseline, immediately after exercise, and 3 hours after exercise. Samples were refrigerated until the end of the session and centrifuged, then refrozen at $-20^{\circ} \mathrm{C}$, and stored until all sessions for each subject were completed.

Salivary cortisol concentrations were measured in duplicate by using a commercially prepared ELISA kit (Diagnostics Biochem Canada, Inc.(DBC) immunoassay kits) with modified procedures suggested by the manufacturer. A lower limit of detection for saliva cortisol was $1.0 \mathrm{ng} / \mathrm{dl}$. CK was assayed spectrophotometrically through the use of commercially available kits. The CV for CK was < 4\%. IgA was assayed by immunodiffusion (SRID) method by use of IgA kit (The Binding Site Ltd., Birmingham, UK), The CV for IgA was $<3 \%$.

Statistical analysis: All results are presented as mean values and standard deviation of the mean. Data were analyzed using a repeated measure ANOVA and LSD post-hoc test. Statistical significance was set at $\alpha=0.05$. Statistical analyses were performed using SPSS version17.0. 


\section{Results}

Results of the analysis showed that during baseline, there were no differences between exercise day (ED) and rest day (RD) for Cortisol, IgA, and CK. After exercise, Cortisol concentration in ED were significantly higher than $\mathrm{RD}(\mathrm{p}<0.05)$; however, IgA and CK responses were not significant between ED and RD. Also, 3 hours after exercise, the Cortisol concentration in ED was significantly higher than in RD ( $\mathrm{p}<0.05$ ); but, IgA and CK concentration 3 hours after exercise was similar in $\mathrm{ED}$ and $\mathrm{RD}$.

Table 2: Mean values $( \pm \mathrm{SD}) \&$ T.Test of Cortisol, $\mathrm{CK}$ and $\mathrm{IgA}$ recorded pre, post- and 3 hours post exercise during rest and exercise day in athletic male.

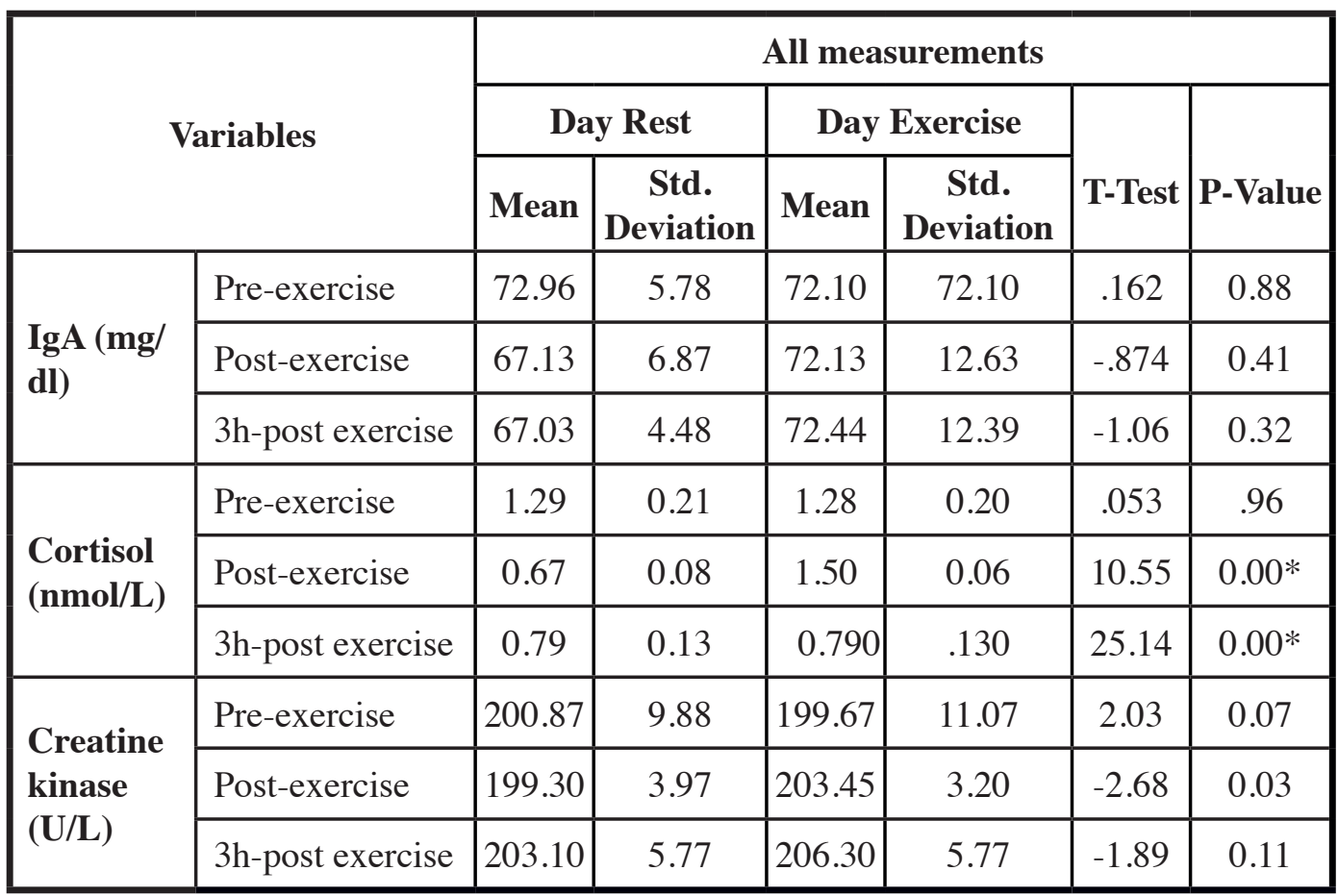

Legend: IgA - Immunoglobulin A

* Significantly $(\mathrm{p}<0.05)$ different from the rest day \& Exercise day. 

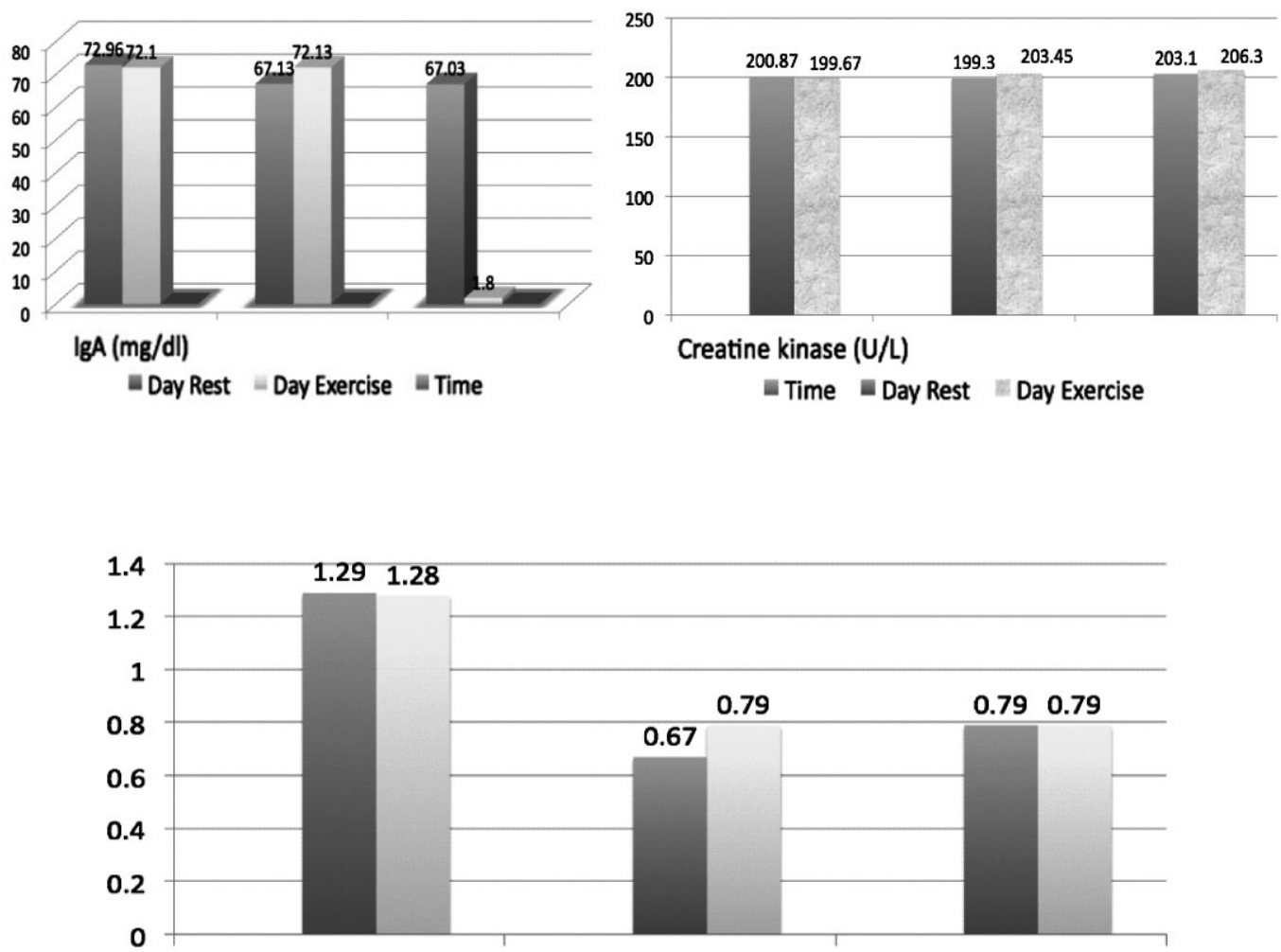

Cortisol (nmol/L)

- Column1 Day Rest Day Exercise 
Table 3. Analysis of F. Test for Cortisol, CK and IgA recorded pre-, post- and 3 hours post exercise during rest and exercise day in athletic male

\begin{tabular}{|c|c|c|c|c|c|c|}
\hline & Variables & $\begin{array}{c}\text { Sum of } \\
\text { Squares }\end{array}$ & df & $\begin{array}{c}\text { Mean } \\
\text { Square }\end{array}$ & F & Sig. \\
\hline IgA & $\begin{array}{c}\text { Between } \\
\text { Groups }\end{array}$ & 383.259 & 5 & 76.652 & .807 & .549 \\
\hline & $\begin{array}{c}\text { Within } \\
\text { Groups }\end{array}$ & 5126.351 & 54 & 94.932 & & \\
\hline Cortisol & $\begin{array}{c}\text { Total } \\
\text { Groups }\end{array}$ & 5509.610 & 59 & & & \\
\hline & $\begin{array}{c}\text { Within } \\
\text { Groups }\end{array}$ & 1.489 & 54 & .028 & & $0.000^{*}$ \\
\hline & $\begin{array}{c}\text { Total } \\
\text { CK }\end{array}$ & 9.561 & 59 & & 58.537 & \\
\hline & $\begin{array}{c}\text { Between } \\
\text { Groups }\end{array}$ & 357.189 & 5 & 71.438 & 1.438 & .226 \\
\hline & $\begin{array}{c}\text { Within } \\
\text { Groups }\end{array}$ & 2682.207 & 54 & 49.670 & & \\
\hline & Total & 3039.396 & 59 & & & \\
\hline
\end{tabular}

Legend: IgA - Immunoglobulin A

* Significantly $(\mathrm{p}<0.05)$ different from the rest day \& day Exercise.

Table 3 showed that there were no correlations between $\operatorname{Ig} \mathrm{A}$ and Cortisol responses to exercise in both days. 


\section{Discussion}

This study focused on IgA, CK, and cortisol response to exercise. Consecutive aerobic and resistance exercise protocol were designed to present physiological stress similar to the preparation phase of training in most sports.

Our results shows that mean salivary concentration of IgA were unaffected by consecutive aerobic and resistance exercise. These results are in line with previous studies (Bishop et al 1999 Nieman et al, 2002 - Volfinger, 1994). Some studies have reported decreases in $\operatorname{IgA}$ concentration following highintensity exercise (Mackinnon et al, 1987-Tharp and Barnes, 1990). Their exercise protocols were undertaken during a period of overtraining (Mackinnon and Hooper, 1994). However, a significant elevation in IgA concentration has also been reported after high-intensity exercise (Blannin et al, 1998). This increase seemed to result from the reduction of saliva flow rate. Previous studies have suggested that there is an intensity-dependent effect of acute exercise on $\operatorname{Ig} \mathrm{A}$, i.e. strenuous exercise is suppressive and moderate exercise has no effect (Mackinnon, 1996). Therefore, the inconsistency in responses of $\operatorname{IgA}$ secretion rate to exercise may be attributed to different types of sympathetic nervous system stimulation during exercise (Hucklebridge et al, 1998). It seems that neither aerobic exercise nor resistance exercise at the same moderate exercise intensity evokes sufficient stimulation of the sympathetic nervous system or of the hypothalamic-pituitary-adrenal axis to modify $\operatorname{IgA}$ transcytosis.

We found that consecutive aerobic and resistance exercise was associated with increased salivary Cortisol concentrations immediately and 3 hours after exercise. Post-exercise Cortisol concentration changes seems to be affected by several mechanisms including stimulation of the sympathetic nervous system, stimulation of hypothalamic- pituitaryadrenal (HPA) secretion, increase of body temperature, changes in blood $\mathrm{pH}$, hypoxia, lactate accumulation, and mental stress (Nieman et al 2006 - Sari-Sarraf et al 2007). A study reported that Cortisol concentration increases due to continued exercises. These researchers reported that physical exercise could stimulate HPA, increase body temperature, increase Cortisol secretion, and the release 
of Cortisol from the carrier proteins (Ben-Aryeh et al, 1989). Therefore, the high concentration of salivary Cortisol accompanied by increase of saliva viscosity is the indicator of sympathetic nervous system activation (Ben-Aryeh et al, 1989). The findings of our study are similar with that of Ben- Aryeh et al, 1989 and Kaciuba-Uscilko et al, 1992, who found that consecutive aerobic exercise and resistance exercise increase Cortisol concentration. Furthermore, the results of this study do not support the data given by O'Connor et al, 1991 and Sari-Sarraf et al, 2007. The equivocal nature of these observations may be due to the difference in intensity, duration, and mode of exercise, the place of exercise, and the age of the subjects in each study.

We found a lack of correlation between $\operatorname{IgA}$ and Cortisol concentrations. Specifically, we observed that $\operatorname{IgA}$ concentration after consecutive aerobic and resistance exercise did not change, while Cortisol concentration changed. Our findings match those of Sari-Sarraf et al, 2007, reporting that during heavy and moderate exercises Cortisol secretion had no relationship with the inhibition of salivary IgA. When the subjects work at a fixed loading, $\mathrm{CK}$ is released from the muscle when the loading exceeds a certain limit of muscle ability (Totsuka et al, 2002). Although numerous studies (Isaacs et al, 1984-Nosaka and Clarkson, 1992-Tokuda et al, 1985) have examined the effects of exercise on serum CK activity under various exercise conditions, to our knowledge no study has addressed CK release during consecutive aerobic and resistance exercise. In the present study, we found that consecutive aerobic and resistance exercise could not increase CK concentration. Previous studies reported that during exercise, muscle repeatedly contracts and uses energy substrates. When exercise intensity is within the normal range of metabolism, the muscle tissue is exercised without marked changes in membrane permeability. However, when exercise intensity exceeds this permissible range, the membrane permeability temporarily changes, resulting in $\mathrm{CK}$ release from the active muscle (Totsuka et al, 2002). Volfinger et al, 1994 indicated the possibility of a threshold value for CK release, with a "distance" threshold for CK release.

Totsuka et al 2002 reported that CK response depends on individual fitness 
level, levels that are usually different between athlete and non-athlete. Our subjects were Athletic Track\& field and maybe the intensity of consecutive aerobic and resistance exercise did not exceed the ability of their muscles, thus the CK concentration in serum did not increase due to consecutive aerobic and resistance exercise.

We conclude that 90-min consecutive aerobic and resistance exercise led to increased salivary Cortisol, but there were no significant changes in salivary IgA and serum CK concentration. Therefore, we suggest that this type of consecutive aerobic and resistance exercise don't show a wide range of deleterious effects on the immune system. Finally, it can only be stated that this kind of consecutive aerobic and resistance exercise was well tolerated; it has demonstrated that this sub-maximal exercise did not lead to muscle damage or altered salivary IgA levels.

\section{References}

1. Ambrose C (1996): Symposium on in vitro studies of the immune responses: III Biochemical agents affecting the inductive phase of the secondary antibody response initiated in vitro. Bacteriol.Rev; 30:408-417.

2. Asahi Y, Yoshikawa T, Watanabe I, Iwasak T, Hasegawa H, Sato Y, Shimada S, Nanno M,
Matsuoka Y, Ohwaki M, Iwakura Y, Suzuki Y, Aizawa C, Sata T, Kurata T, Tamura S (2002): Protection against influenza virus infection in polymeric Ig receptor knockout mice immunized intranasally with adjuvantcombined vaccines. J.Immunol; 168: 29302938.

3. Ben-Aryeh H, Roll N, Lahav M, Dlin R, Hanne-Paparo N, Szargel R, Shein-Orr C, Laufer D (1989): Effect of exercise on salivary composition and cortisol in serum and saliva in man. J.Dent.Res; 68:1495-1497.

4. Bishop N, Blannin A, Robson P, Walsh N, Gleeson M (1999): The effects of carbohydrate supplementation on immune responses to a soccerspecific exercise protocol. J.Sports.Sci; 17: 787-796.

5. Bishop N, Blannin A, Walsh N, Armstrong E, Rickman M, Gleeson M (2000): Carbohydrate and fluid intake affect the saliva flow rate and IgA response to cycling. Med.Sci. Sports.Exerc; 32:2046-2051.

6. Blannin A, Robson P, Walsh N, Clark A, Glennon L, Gleeson M (1998): The effect of exercising to exhaustion at different intensities on saliva immunoglobulin A, protein and electrolyte secretion. Int.J.Sports.Med; 19:547-552.

7. Czyżewska-Buczyńska A, LewandowiczUszyńska A., Jankowski A. (2007): IgA, an essential part of the immune system: selected issues. Post. Hig. Med. Dosw. ; 61:38-47.

8. Daly W, Seegers C, Dobridge J, Hackney A (2005): Relationship between stress hormones and testosterone with prolonged endurance exercise. Eur. J. Appl. Phsiol.; 93:375-380.

9. Dohi K, Mastro A, Miles M, Bush J, Grove D, Leach S, Volek J, Nindl G, Marx J, Gotshalk L, Putukian M, Sebastianelli W, Kraemer W (2001): Lymphocyte proliferation in response to acute heavy resistance exercise in women: influence of muscle strength and total work. Eur.J.Appl.Physiol; 85:367-373. 
10. Fleshner $\mathrm{M}(2000)$ : Exercise and neuroendocrine regulation of antibody production: protective effect of physical activity on stress-induced suppression of the specific antibody response. Int.J.Sports.Med; Suppl1:14-19.

11. Fox E (1973): A simple, accurate technique for predicting maximal aerobic power. J.Appl. Physiol; 35:914-916.

12. Gleeson M, McDonald W, Pyne D, Cripps A, Francis J, Fricker P, Clancy R (1999) :Salivary IgA levels and infection risk in elite swimmers. Med.Sci.Sports.Exerc; 31(1):67-73.

13. Gleeson M (2000): Mucosal immune responses and risk of respiratory illness in elite athletes. Exerc. Immunol. Rev.; 6:5-42.

14. Gleeson M and Pyne D, (1993): Special feature for the Olympics: effects of exercise on the immune system: exercise effects on mucosal immunity. Immunol.Cell.Biol; 78:536-544.

15. Herbert $T$ and Cohen S (1993): Stress and immunity in humans: a meta-analytic review. Psychosom.Med; 55:364-379.

16. Houmard J, Costill D, Mitchell J, Park S, Fink W, Burns J (1990): Testosterone, cortisol, and creatine kinase levels in male distance runners during reduced training. Int.J. Sports.Med., $11: 41-45$.

17. Hucklebridge F, Clow A, Evans P (1998): The relationship between salivary secretory immunoglobulin A and cortisol: neuroendocrine response to awakening and the diurnal cycle. Int.J.Psychophysiol; 31:69-76.

18. Isaacs D, Webster A, Valman H (1984): Immunoglobulin levels and function in preschool children with recurrent respiratory infections. Clin.Exp.Immunol; 58:335-340.

19. Jemmott $J$ and Mcclelland D (1989): Secretory IgA as a measure of resistance to infections disease: Comment on Stone, Cox, Valdimarsdottir, and Neale. Behavioral.Med; 15:63-71.
20. Kaciuba-Uscilko H, Kruk B, Szczpaczewsk M, Opaszowski B, Stupnicka E, Bicz B, Nazar K (1992): Metabolic, body temperature and hormonal responses to repeated periods of prolonged cycle-ergometer exercise in men. J.Appl.Physiol; 64:26-31.

21. Kirwan J, Clarkson PM, Graves J, Litchfield P, Byrnes W (1986): Levels of serum creatine kinase and myoglobin in women after two isometric exercise conditions. Eur .J.Appl. Physiol., 55:330-333.

22. Lamm M (1998): Current concepts in mucosal immunity. IV. How epithelial transport of IgA antibodies relates to host defense. Am.J.Physiol; 274:G614-G617.

23. Ljungberg G, Ericson T, Ekblom B, Birkhed D (1997): Saliva and marathon running. Scand .J.Med.Sci.Sports; 7:214-219.

24. Mackinnon L, Chick T, Van A, Tomasi T (1987): The effect of exercise on secretory and natural immunity. Adv.Exp.Med.Biol., 216A:869-876. Immune response to consecutive exercise.

25. Mackinnon L (1992): Exercise and Immunology. Champaign IL: Human Kinetics.

26. Mackinnon L (1996): Immunoglobulin, antibody and exercise. Exerc.Immuno.Rev., 2:1-34.

27. Mackinnon L and Hooper S (1994): Mucosal (secretory) immune system responses to exercise of varying intensity and during overtraining. Int.J.Sports.Med; 15:S179-S183.

28. Macpherson A, McCoy K, Johansen F, Brandtzaeg P (2008): The immune geography of $\operatorname{IgA}$ induction and function. Immunology; 1:11-22.

29. McDowell S, Chaloa K, Housh T, Tharp G, Johnson G (1991) : The effect of exercise intensity and duration on salivary immunoglobulin A. Eur J.Appl.Physiol; 63:108-111.

30. McGhee J, Mestecky J, Elson C, Kiyono H (1989): Regulation of IgA synthesis and immune response by $\mathrm{T}$ cells and interleukins. J. Clin. Immunol ; 9:175-199. 
31. Mestecky J, Lue C, Tarkowski A, Ladjeva I, Peterman J, Moldoveanu Z, Russell M, Brown T, Radl J, Haaijman J, Kiyono H, McGhee J (1989) :Comparative studies of the biological properties if human IgA subclasses. Protides Biol. Fluids; 36:173-182.

32. Newham D, Jones D, Clarkson P (1987): Repeated high force eccentric exercise: effects on muscle pain and damage. J.Appl.Physiol; 63:1381-1386.

33. Nieman D, Henson D, Sampson C, Herring J, Suttls J, Conley M (1995): The acute immune response to exhaustive resistance exercise. Int.J.Sports.Med; 16:322-328.

34. Nieman D, Henson D, Fagoaga O, Utter A, Vinci D, Davis J, Nehlsen-Cannarella S (2002): Change in salivary IgA following a competitive marathon race. Int.J.Sports. Med; 23:69-75.

35. Nieman D, Henson D, Dumke C, Lind R, Shooter L, Gross S (2006) :Relationship between salivary IgA secretion and upper respiratory tract infection following a $160-\mathrm{km}$ race. J.Sports.Med.Phys.Fitness; 46:158-162.

36. Nieman D, Kernodle M, Henson D, Sonnenfeld G, Davis J (2000): Acute immune responses to tennis drills in adolescent athletes. Res.Quartly. Exerc.Sport; 71:403-408.

37. Nosaka K and Clarkson P (1992): Relationship between post-exercise plasma CK elevation and muscle mass involved in the exercise. Int.J.Sports.Med; 13:471-475.

38. O'connor P, Morgan W, Reglin J (1991): Psychobiologic effect of 3D of increased training exercise intensities on salivary cortisol. J.Strength.Cond.Res; 16:286-289.

39. Ostergaard P (1977): IgA levels, bacterial carrier rate, and the development of bronchial asthma in children. Acta.Pathol. Microbiol. Scand; 85:187-195.
40. Pedersen B and Hoffman-Goetz L (2000): Exercise and the immune system: regulation, integration, and adaptation. Physiol.Rev; 80:1055-1081.

41. Proctor G and Carpenter G (2007): Regulation of salivary gland functions by autonomic nerves. Auton. Neurosci. ; 133:3-18.

42. Rahimi R, Ghaderi M, Mirzaei B, Ghaeni S, Faraji H, Sheikholeslami-Vatani D, RahmaniNia F (2010): Effects of very short rest periods on immunoglobulin A and cortisol responses to resistance exercise in men. J.Hum.Sport.Exerc; 5:146-157.

43. Sari-Sarraf V, Reilly T, Doran D, Atkinson G (2007) :The effects of single and repeated bouts of soccer-specific exercise on salivary IgA. Arch.Oral.Biol; 52:526-532.

44. Tharp G and Barnes M (1990): Reduction of saliva immunoglobulin levels by swim training. Eur.J.Appl.Physiol; 60:61-64.

45. Tharp G (1991): Basketball exercise and secretory immunoglobulin A. Eur.J.Appl. Physiol., 63: 312-314.

46. Tokuda S, Iiboshi A and Otsuji S (1985): Biphasic changes and characteristics in serum creatine kinase activity due to transient weight training. Jpn.J.Phys.Fitness.Sports.Med; 34:218-224.

47. Totsuka M, Nakaji S, Suzuki K, Sugawara K, Sato K (2002): Break point of serum creatine kinase release after endurance exercise. J.Appl. Physiol; 93:1280-1286.

48. Volfinger L, Lassourd V, Michaux J, Braun J, Toutain P (1994): Kinetic evaluation of muscle damage during exercise by calculation of amount of creatine kinase released. Am.J. Physiol. Regul.Integr.Comp.Physiol; 266:R434-R441.

49. Walsh N, Blannin A, Clark A, Cook L, Robson J, Gleeson M (1999): The effects of high-intensity intermittent exercise on saliva IgA, total protein and alpha-amylase. J.Sports; 17:129-134. 